the right eye is now 0.9. The binocular sight is normal. In this case, exercises for six days sufficed to cure a marked ametropia, complicated by astigmatism, and a double deviation, one of which was quite considerable. Seen two months later, the sight of Miss M-_ remained perfect.

\title{
Conclusion
}

Owing to its double nervous and optical origin, convergent strabismus requires a treatment that is lengthy and particularly difficult to establish, but in which re-education of binocular vision is essential. Where possible this constitutes the preferable method, as well as the indispensable complement to surgical intervention. We ought to beware of the opinion of a great number of excellent oculists who believe divergent strabismus can only be relieved by surgery. With some reservations we hold the contrary to be the truth, and it is chiefly in this case that orthoptic treatment gives the most rapid results and brilliant successes.

\section{GLIOMA RETINAE (WITH REPORT OF A CASE)}

BY

\author{
Dr. M. J. KeYS \\ VICTORIA, B.c.
}

True glioma retinae is seen so rarely and the subject is so interesting that it warrants publication of the details of every case observed.

The following case recently occurred in my own practice :-

Case History.-J. D., female, was born in the Jubilee Hospital, Victoria, two and a half years ago. She is the only child in the family. Mother pregnant but once. Parents : father, English ; his mother was Scotch. The mother of the child is English, born in Lancashire; no history of any similar eye trouble on either side of the house. The little patient when born was a healthy baby, labour was normal, and she has never had a day's illness in her life, not even the diseases common to childhood, and when first seen by me, September 28, 1920, was a well-nourished, healthy child.

History of present illness.-About two weeks previously, a lady, one of the neighbours, drew the attention of the mother to the peculiar appearance of the child's right eye, and about the same time the child's cousin, a lad of 12 years of age, noticed the same thing, and curiously enough, remarked that it looked like a " cat's 
eye in the dark." The parents then began to study the eye and noticed in looking at this eye from the temporal side that it had a peculiar white appearance in its interior. On September 28 the child was brought to my office for examination, with the history as given above.

Examination.-Tension of the right eye increased, lids and conjunctiva normal, cornea clear, no signs of posterior synechiae or cyclitis or " k.p.," the pupil slightly dilated and fixed. In looking at the eye from the temporal side the white appearance of the interior was quite apparent. The pupil was further dilated with homatropin and cocain and the ophthalmoscopic examination revealed the media clear, but a tumour mass could be seen springing from the lower nasal side of the fundus and projecting forward. No blood vessels were apparent on the growth, which presented an appearance very like absorbent cotton. The temporal side of the retina had the usual red reflex, but towards the growth this diminished, and approaching the growth the reflex was lost. No effort was made to test the vision in this eye. Vision in the left eye was normal and has remained so.

Diagnosis.-I concluded from the history and examination, particularly the absence of any trauma, of disease or sickness of any kind, that I had to deal with a glioma, keeping in mind the possibility of a pseudo-glioma. I explained the seriousness of the condition to the mother and advised immediate enucleation. Dr. Scott-Moncrieff, of the City of Victoria, saw the case and agreed with the diagnosis and concurred in the treatment. The parents consented at once to the removal of the eye.

Operation.-On September 30 the eye was removed in the usual way, with this exception : after the muscles were severed the optic nerve was grasped with curved artery forceps and cut between the forceps and the eyeball. The nerve was then put on the stretch and cut behind the artery forceps. This portion of the nerve, with the eye, was sent to the pathologist for examination. The eye was noticeably enlarged, as it was difficult to get it through the palpebral fissure after its separation. The wound in the conjunctiva healed without incident.

Pathologist's report.- " The retina is completely detached in this specimen and almost completely involved. Only a very small portion can be recognized as retina. The optic disc is involved. While the sclera does not appear to be involved in this particular section there is extra-ocular extension of the growth into the loose tissue about the ball.

Diagnosis.-Glioma exophytum.

(Signed)-J. H. Moore."

Subsequent history.-After receiving the Pathologist's report to the effect that the growth was gliomatous, I advised the parents 
to have the orbit exenterated, but they refused, saying that they would rather lose the child than have this deformity, so at the end of two weeks an artificial eye was inserted, and as the parents lived twelve miles from town the child was seen only occasionally. Two months after enucleation the mother brought the child again to the office, stating that they had noticed that the artificial eye was being displaced inwards. Examination revealed a tumour mass, soft in consistency, about the size of a small marble, under the conjunctiva, situated slightly to the temporal side. I explained to the parents that the growth had recurred and advised as a last resort the exenteration of the orbit and the use of radium. 'But they again refused as I could not promise them a complete cure, but they had heard of cures in other cases of malignancy, so two weeks afterwards they decided to have the second operation done. On December 17 the orbit was exenterated and the Pathologist's report was to the effect that the growth was gliomatous. On December 23, January 3, 7, 14, 21, and February 12, 20 milligrams of radium were placed between the lids and left there in each instance about five hours, but the growth again showed symptoms of recurrence and the use of radium was abandoned. The growth gradually increased in size. The child was seen from time to time and the growth kept gradually increasing. The child has slowly lost in weight, has lost her appetite and is irritable, sleeps badly, mostly under the influence of paregoric, but her mental condition has remained good. On June 11 photographs were taken, and it was noticed that there was a large tumour mass originating in the eye socket and protruding forward, looking very much like a truncated horn. The surfaces are fungating and bleed very readily, and the whole mass emits a sickening, musty odour. The nose is forced to the left and is almost covered by the tumour mass. The right nares is closed so that the secretions find their way backwards into the naso-pharynx and thence into the throat. The photograph also shows a large smooth tumour mass situated on the right lower jaw, at first bluish in colour due to venous stasis. The surface is also smooth and glistening. This tumour extends to the right clavicle, below and well beyond the middle line in front. Behind it extends beyond the middle line and as high as the occiput. Above it extends almost to the top of the ear. The lower pendulous portion is soft and fluctuating, evidently containing pus. Superimposed upon this mass is another smaller fluctuating tumour about the size of a hen's egg, located at the site of the pre-auricular gland. There is another tumour mass about the size of a walnut at the postparietal area in the mid-line. On the left side the sub-maxillary glands are enlarged and the whole chain of cervical glands are palpable as far down as the clavicle. No glandular enlargement below the clavicle on either side. 
In the sulcus between the fungating mass and the tumour mass of the jaw pus is exuding posteriorly.

July 6 : The horn-like mass above described has enlarged in size to such an extent that the child's nose is buried under the growth and extends beyond the middle line, obscuring the vision of the left eye. That portion of the superior maxilla on right side containing the teeth is forced to the left about a quarter to a half-inch. The mouth is distorted so that the taking of medicine and nourishment is difficult. The large tumour mass of the right jaw has also enlarged in size, has also increased in venous stasis, and the growth projects beyond the clavicle. The child is now confined to its crib and refuses nourishment. Death will probably take place shortly, no doubt from exhaustion.

The subject of glioma retinae is interesting, not only on account of the nature of the tumour concerning which there is always some difference of opinion, but also on account of its comparative rarity. According to statistics the tumour is only observed once in 10,000 cases ordinarily presented in ophthalmological practice, so that the average ophthalmologist may not have the opportunity of observing a tumour of this kind in his ordinary practice.

I am deeply indebted to Dr. Paul D. Berrisford, of St. Paul, Minn., for his interest in this case, and for valuable notes drawn from his article, "Statistical Notes on Glioma Retinae,"(1) in which he brings the cases of glioma in the Moorfields Hospital, London, practically up-to-date, and he writes me recently that there has been practically nothing new on glioma since 1916 . The cases in Moorfields Hospital were written from 1871 to 1905 by Lawford and Collins, ${ }^{(2)}$ Marshal, ${ }^{(3)}$ and Owen, ${ }^{(4)}$ and Dr. Berrisford has brought them up-to-date.

Definition.-The first accurate and scientific description of the tumour was written by Wardrop ${ }^{(5)}$ in 1809 , based on the study of 17 cases. In $1853 \mathrm{Virchow}^{(6)}$ published the result of his exhaustive clinical and pathological research.

Both Wardrop and Virchow observed the similarity between glioma and the white substance of the brain. The term glioma retinae due to Virchow does not seem to be strictly correct. $\mathrm{O}^{\prime}$ Connor $^{(7)}$ remarks that a glance at the literature of gliomatous growths will show manifold variations in those cases in which the retina was entirely obliterated in the tumour mass, and others in which the layer of rods and cones was demonstrated to be clearly free from participation in the pathological process. The point is fully discussed by Flexner ${ }^{(8)}$.

Flexner and Wintersteiner ${ }^{(9)}$ contend that the correct nomenclature is neuroepithelioma, as the tumours have their origin in the neuroepithelial layer of the retina, but the old term is retained on account of its general use, at the same time being more 
comprehensive. It is also called sarcoma of the retina and fungus haematodes oculi, a term used by the older authors. Beer ${ }^{(10)}$ called it amaurotic cat's eye. The tumours are subdivided by Hirschberg(11) (12), according to their location and direction of growth into exophytum and endophytum. In glioma exophytum the growth proceeds towards the choroid after the retina has been detached. It finally reaches the choroid and spreads out superficially and may go as far as the anterior chamber, or vessels may grow out from the tumour into the choroid accompanied by tumour cells. In glioma endophytum the growth is attached but loosely to the retina and grows forward into the vitreous, and as a rule the growth completely fills the eye. This form of growth is the more rare.

Histology.-All are agreed that this neoplasm originates in the granular layers of the retina and most commonly in the inner granular layer. The tumour is composed of small cells in a very soft basement substance. The cells consist of a definite nucleus surrounded by scanty protoplasm, which in many cases possess processes. The cells follow the blood vessels and on account of their rapid growth may take the appearance of tubular glands. Some are glia cells and others are ganglion cells. Degeneration in the intercellular substance takes place early.

Cause.-The cause of glioma is unknown.

Age.-The disease is one of infancy and childhood, no true cases having been known after the age of sixteen, according to the Moorfields Hospital report covering 135 cases from birth to seven years of age. The highest percentage was found to occur during the second year of life, gradually increasing from infancy to that age, then receding till there were only two cases in the 135 at the age of seven years; 56 cases or 41 per cent. were first noted before the thirteenth month; 26 cases during the second year-only two cases being reported in the seventh year.

Frequency.--Quoting again from Berrisford's report at Moorfields Hospital. Between the years 1871 and 1913, covering 42 years, the total number of outpatients numbered 1,259,452. Out of this number there occurred 131 cases of glioma retinae, or roughly, 1 in 9,600 cases, or .01 per cent. Other authors have about the same percentages.

Sex.-Males and females are affected about equally, with the balance slightly in favour of males. In 792 cases collected from many different sources there were 398 males, 361 female, and 33 cases in which the sex was not stated.

Eye affected.-In 25 per cent. of cases both eyes are affected, the disease originating in the second eye independently of the first, and not passing by continuity through the chiasma.

Metastases.-Wintersteiner, in his work, gives an interesting 
report as to the relative frequency with which the various parts of the body become involved in the metastatic process. I quote :Brain and membranes-43 times,

Skull and bones of the face- 40 times, Lymphatic glands-36 times,

Parotid gland-9 times,

Skeleton bones-9 times,

Liver- $\boldsymbol{\tau}$ times,

Spinal cord and membranes-5 times,

Kidneys-2,

Ovaries-2,

Lungs-1,

Spleen-1.

It is interesting to note in the case reported that the bones of the face were affected, also lymphatics and parotid gland, but the brain was apparently not involved.

Congenital aspects and family history.-Professor Fuchs says that a congenital morbid disposition; or, as he aptly puts it, "a congenital vice of development," very often lies at the bottom of glioma, and he says that often it is observed at such an early age that the beginning must be dated back to foetal life. This prenatal origin calls to mind a statement of Treacher Collins: "That a microscopical specimen of a foetal retina at three months with layers undifferentiated, is such that if shown to a pathologist it would be pronounced by him as glioma."

That the disease runs in families is beyond doubt. Many striking cases are on record. The following reported by Berrisford will suffice :-

The Grover family is very interesting. Thomas Grover was operated on in 1859 when five months old, the left eye being removed for glioma. He survived and had a family of two children. The son Frank had his eye removed at three years and died at the age of fifteen from paralysis. The daughter Beatrice Wallbank's first three children all died at four years with glioma, two of them having bilateral glioma. The next four children were all healthy, but the eighth-the last child, died at three years from double glioma. Professor Fuchs records a case in his text book in which a child of four years died of brain symptoms following removal of a gliomatous eye. Later on the brother, aged two, was found to have the same trouble in an eye blind from birth, and died from double glioma. A third child was suspected of having glioma, but the trouble proved to be coloboma of iris and choroid. Newton reports a case where ten out of sixteen in the same family died with glioma.

Glioma in a shrunken eye.-The presence of glioma in a shrunken eye is a rare condition, only about twenty cases are 
recorded in all literature. Dr. Denis O'Connor, of Worcester, Mass. ${ }^{(7)}$ records a very interesting case in an infant in which the shrunken right eye was removed and was found to be gliomatous. The child died later on from glioma of the left eye without recurrence in the right. His conclusions are to the effect that after destruction of the retina the necrosis progressed, the necrotic masses being replaced by connective tissue, which in turn is invaded, and the cycle is repeated until finally the eye became quiescent, having undergone necrosis and calcification, through, as he thinks, insufficient blood supply; but he further states that some of these cases finally die of recurrences, and he records many of these cases as pseudo-gliomata, or as an episode in the course of true glioma preparatory to further advance. This probably explains the cure by ophthalmologists of one hundred years ago, who resorted at that time only to antiphlogostic, alternative, and derivative treatment.

Differential diagnosis.-In making differential diagnosis the history of the case, as well as the family history, is important. One must enquire for history of injuries to the eye, and ascertain if the child has had meningitis or other infectious diseases common to childhood, and the signs of iridocyclitis and keratitis punctata must be looked for. The rare diseases, such as :-

Acute suppurative hyalitis,

Cysticercus in the vitreous,

Retinitis circinata,

Detachment of the retina with dropsical degeneration of the visual cells.

as reported by de Schweinitz, must be kept in mind as a possibility. Simple detachment of the retina and leukosarcoma are both rare conditions in childhood. A corneal cicatrization or staphyloma may obstruct the pupillary space; or, in the glaucomatous stage of glioma, a hyphaema or cataract may obscure or prevent ophthalmoscopic examination, or haemorrhage into the vitreous may become organized and render the diagnosis difficult. Persistent vascularity of the lens capsule or hyaloid artery with posterior polar cataract may also lead to a wrong diagnosis. Tubercle of the choroid and chronic inflammatory processes in the choroid and ciliary body are the two conditions that call for careful discrimination, and often a positive diagnosis cannot be made until after the eye is removed. A report from Moorfields Hospital from 1888 to 1893 indicated that seven of twenty-four eyes enucleated for glioma were pseudo-glioma. In the case reported all the clinical symptoms were present with one exception-the tumour mass did not show vascularization, which is the rule.

Recurrences.- The prognosis on the whole is very bad. It is only favourable when operation is done early and when the tumour 
does not extend beyond the retina. At least three years must elapse after enucleation before we can count on a permanent cure. In the meantime the other eye may become affected or metastases may take place. We can count on a permanent cure only when the optic nerve is intact and the tumour is confined to the retina. The percentages of recovery given are small. Hirschberg figures on 6.5 per cent.; Wintersteiner 13.7 per cent.; Vossius 10 per cent. In the Moorfields Hospital report the percentage of cures is not given on account of the difficulty of tracing some of the cases, but Berrisford considered 9 out of the 41 cases enumerated by him as cured, more than three years having elapsed since enucleation.

Fuchs, in his text book, states that three cases of glioma have been reported as recovering spontaneously by shrivelling. De Kleijn ${ }^{(13)}$ reported 18 cases of glioma retinae operated upon in Utrecht with eight recoveries. In four of these recoveries the optic nerve was free; in two the affection was peripheral; in one the optic nerve was completely involved as far as the section; in one the amount of involvement is not stated. In the case where the optic nerve was involved the other eye became blind later and had to be removed.

Seventeen cases were reviewed by Hirschberg, of which ten at the time of operation had not extended beyond the retina, and in none of these latter had a relapse occurred during a period of from 5 to 13 years subsequent to operation.

The radium treatment was carried out in the Department of Radiology and Electro-therapeutics of the Provincial Royal Jubilee Hospital, Victoria, B.C., under the direction of Dr. L. K. Poyntz. Dr. Poyntz thinks that while there are grounds for supporting the view that the more malignant a tumour is the more vulnerable it is to massive radiotherapy, yet it must be admitted that the rays may stimulate rather than destroy tumour masses. It is possible that radium had a stimulating effect in the present case.

Dr. Poyntz thinks that it is probable that a preparatory irradiation before enucleation, complete fulguration of the contents of the orbit at the time of operation, if followed by intense radium treatment of those sites where recurrence is more common, might be a rational treatment of this type of case.

Verhoeff ${ }^{(15)}$ quite recently reported that there were in literature only two cases in which an eye containing a glioma retinae was treated by radiation with apparent success. These cases were reported by Hilgartner and Schoenberg. Verhoeff himself reports a case in which, six months after enucleation of the right eye for glioma, followed immediately by severe X-raying, a tumour developed in the left eye. This was immediately treated by 
$\mathrm{X}$-rays. This tumour, though it had given rise to intraocular metastases, had not invaded the optic nerve. Although Verhoeff had not the opportunity to verify this tumour histologically he thinks there can be little doubt that it was a glioma. Although it persists yet the child's vision following the X-ray treatment appears to be perfect for the $3 \frac{1}{2}$ years following treatment.

\section{REFERENCES}

1. Berrisford, P. D.- " Statistical Notes on Glioma Retinae, with a Report of 41 Cases." Roy. Lond. Ophth. Hosb., Reports, 1916, Vol. XX, Part ii.

2. Lawford and Collins.-Roy. Lond. Ophth. Hosp. Reports, 1895-97, Vol. XIII, p. 12.

3. Marshall.-Roy, Lond. Ophth. Hosp. Reports, 1895-97, Vol. XIV, p. 456.

4. Owen.-Roy. Lond. Ophth. Hosp. Reports, 1905, Vol. XVI, p. 323.

5. Wardrop. - "Observations on Fungus Haematodes," Monograph, Edinburgh, 1809.

6. Virchow. - Cited by O'Connor.

7. O'Connor, D. F.-“"Glioma Retinae et Atropia Bulbi," Arch. of Ophth., 1917, Vol. XLVI, p. 298.

8. Flexner.-Bull. Johns Hopkins Hosp., 1891, Vol. II, p. 115.

9. Wintersteiner.-Das Neuro-Epithelioma Retinae, Leipzig, 1897, and Arch. $f$. Augenheilk., 1895, Vol. XXXII, p. 154.

10. Beer.-Cited in $\Lambda$ xenfeld's "Lehrbuch d. Augenheilk.," p. 586.

11. Hirschberg.- “ Der Markschwamm der Netzhaut," Monograph, Berlin, 1809.

12. Hirschberg. - "Ueber der Markschwamm der Netzhaut," Centralbl. $f$. prak. Augenheilk., 1904, Vol. XXVIII, p. 97.

13. De Kleijn.-Arch. f. Ophthal., 1912, Vol. LXXX, p. 2371.

14. See Amer. Encyclopedia of Ophth., Vol. VII, p. 582, et seq.

15. Verhoeff.-Arch. of Ophthal., 1921, Vol, L, p. 450.

\section{CENTRAL SCOTOMA IN ANTERIOR UVEITIS*}

\section{By}

J. Gray ClegG, M.D., B.S., F.R.C.S.

MANCHESTER

At the Manchester meeting on October 14, 1921, I read a preliminary note on this subject and showed a case (No. 1).

The disease is that frequently described as irido-cyclitis with the so-called keratitis punctata. I do not wish to attempt to deal either with its causation or its treament, both of which are obscure, but rather to record some personal observations on the occurrence of a definite central or paracentral scotoma. The scotoma in the cases recorded is not due to any diseased state at the posterior pole which the ophthalmoscope would reveal.

The scotoma may be relative or absolute, evanescent or permanent.

The explanation is as yet not quite clear. At present my view

* A paper read at the Sheffield Meeting of the North of England Ophthalmological Society, November 11, 1921. 